\title{
Case Report \\ Progressive Multifocal Leukoencephalopathy in HIV-Infected Children: A Case Report and Literature Review
}

\author{
Peninnah Oberdorfer, ${ }^{1}$ Charles H. Washington, ${ }^{2}$ Kamornwan Katanyuwong, ${ }^{3}$ \\ and Podjanee Jittamala ${ }^{1}$ \\ ${ }^{1}$ Division of Infectious Diseases, Department of Pediatrics, Faculty of Medicine, Chiang Mai University, Chiang Mai 50200, Thailand \\ ${ }^{2}$ Department of Epidemiology, Bloomberg School of Public Health, Johns Hopkins University, Baltimore, MD 21205, USA \\ ${ }^{3}$ Division of Neurology, Department of Pediatrics, Faculty of Medicine, Chiang Mai University, Chiang Mai 50200, Thailand
}

Correspondence should be addressed to Peninnah Oberdorfer, aoberdor@med.cmu.ac.th

Received 2 February 2009; Accepted 13 June 2009

Recommended by Deepak Kamat

We report a case of a perinatally HIV-infected patient aged 9 years, who presented with right-sided hemiplegia. His initial CD4 T-cell was of $0.21 \%(4$ cells $/ \mu \mathrm{L})$ and plasma HIV RNA virus of 185976 copies/mL (log 5.27). Plasma and CSF samples were subsequently positive for JCV. Twelve days after the initiation of highly active antiretroviral therapy (HAART), the MRI showed progressive white matter lesions with asymmetrical deep and subcortical white matter lesions over the left frontotemporoparietal region and the right frontal lobe. Immune Reconstitution Inflammatory Syndrome (IRIS) was suspected, and the patient was treated with methylprednisolone. His clinical symptoms worsened and despite therapy the patient deteriorated.

Copyright ( 2009 Peninnah Oberdorfer et al. This is an open access article distributed under the Creative Commons Attribution License, which permits unrestricted use, distribution, and reproduction in any medium, provided the original work is properly cited.

\section{Background}

Progressive multifocal leukoencephalopathy (PML) is caused by the JC virus (JCV). As a demyelinating disease, PML typically presents with altered mental status, motor deficits, and ataxia, and is associated with immunosuppression, especially human immunodeficiency virus (HIV) [1]. Prevalence of JCV specific antibodies increases rapidly during childhood, but the mode of transmission is unknown [2]. PML is rare in HIV-infected children and even more uncommonly associated to immune reconstitution inflammatory syndrome (IRIS) in children.

\section{Case Report}

2.1. First Admission. A previously healthy 9-year-old boy (whose mother was recently found to be HIV-positive) presented to the hospital with 1 week of right-sided hemiplegia and right-sided facial palsy. Past medical history included psoriasis, diagnosed 4 years prior. His only HIV exposure was perinatal. On exam the patient weighed 22 kilograms, and vitals signs were within normal limits. He was alert and oriented with a normal level of consciousness and responded appropriately to questions. His speech was slowed and slurred, but this was his baseline according to his mother. He had right-sided facial palsy and right-sided tongue deviation; otherwise cranial nerves were intact. The boy had $3 / 5$ strength in the right upper extremity and 4/5 strength in the right lower extremity. Left-sided strength was $5 / 5$. The patient was able to walk with limited difficulty. Deep tendon reflexes were $2+$ and $3+$ throughout. Babinski's sign showed dorsiflexion of the right 1 st toe. Sensation was intact throughout. The patient also had clusters of 1-2 mm skin colored papules on his forehead and left cheek in addition to diffuse mild psoriatic scaling. Immunizations were up to date. The patient was admitted for a workup of these symptoms.

Laboratory studies showed complete blood count: hematocrit $31.6 \%$, hemoglobin $10.5 \mathrm{~g} / \mathrm{dL}$, white blood cell count 5000 cells/ $\mu \mathrm{L}$ (N 41\%, L 35\%, E 12\%, M 6\%, B 1\%, atypical L 1\%), and 157000 platelets/ $\mu \mathrm{L}$. HIV-antibody test was positive with a CD4 T-cell $0.21 \%(4$ cells $/ \mu \mathrm{L})$ and plasma 


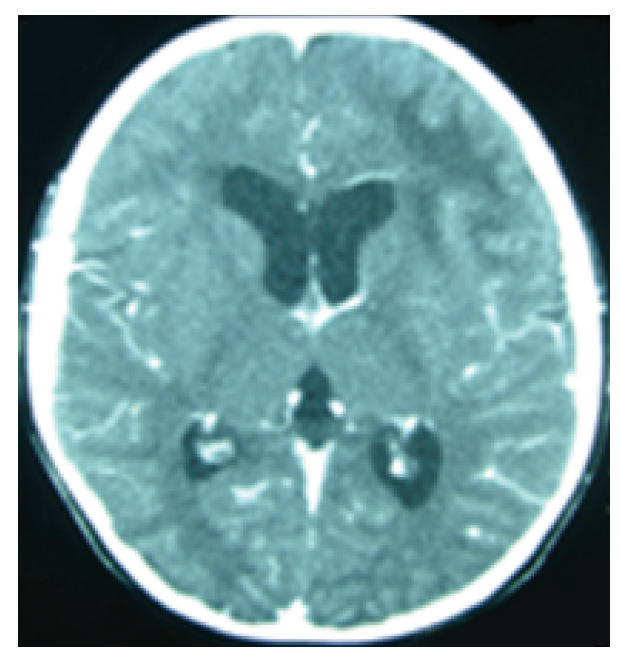

FIgURE 1: CT on day 30 of onset of symptoms and 1 week postHAART initiation.

HIV RNA virus of 185976 copies/mL ( $\log 5.27)$. Tests for Cryptococcus antigen, Toxoplasmosis antigen, Ebstein Barr virus IgG and IgM, Cytomegalovirus IgG and IgM, Hepes Simplex virus polymerase chain reaction (PCR), Japanese encephalitis as well as cultures for tuberculosis and fungi (plasma and cerebrospinal fluid, CSF) were all negative. Plasma and CSF samples were positive for JCV by real time PCR with a plasma RNA level of 226 copies $/ \mathrm{mL}$.

Three days after admission a brain computerized tomography (CT) scan was performed and showed frond-like hypodense lesion at the left frontal lobe with mild effacement of the left frontal horn of the lateral ventricle. Highly active antiretroviral therapy (HAART) regimen was subsequently started 10 days after admission, consisting of GPOvir-Z (coformulated zidovudine $250 \mathrm{mg}$, lamivudine $150 \mathrm{mg}$, and nevirapine $200 \mathrm{mg}$ ) [3]. Clinically, the patient deteriorated during the 1st and 2nd weeks of HAART with fever and increased right leg weakness, but immunologic and virologic improvement was seen $(\mathrm{CD} 4 \mathrm{~T}$-cell count $0.8 \%, 10$ cells $/ \mu \mathrm{L}$, and a plasma HIV RNA viral level of 26532 copies/mL, log 4.42). CT (Figure 1) and brain magnetic resonance imaging (MRI; Figure 2) scans were subsequently performed. The scans showed progressive of white matter lesions with asymmetrical deep and subcortical white matter lesions over the left frontotemporoparietal region and the right frontal lobe. The lesion on the left hemisphere involved internal capsule, lentiform nucleus, thalamus, and genu of corpus callosum and anterior cerebellar hemisphere. There were no enhanced areas after the contrast study.

The patient was discharged 7 weeks after the first admission. Upon discharge he was able to walk with assistance, but was unable to speak.

2.2. Second Admission. The patient was readmitted one day after discharge due to autonomic nervous system dysfunction (nausea, vomiting, and loss of bowel and bladder tone).

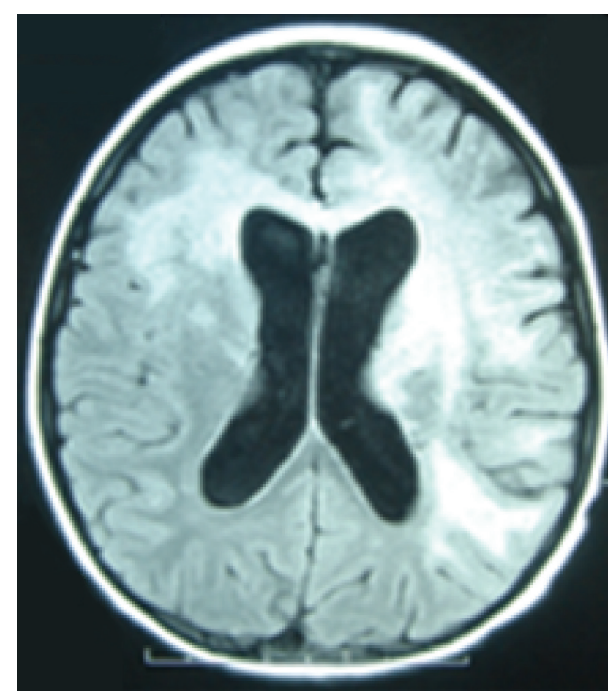

FIGURE 2: MRI on day 38 of onset of symptoms and 2 weeks postHAART initiation.

Deep tendon reflexes were $4+$ throughout, and Babinski was positive bilaterally. Continued improvement of immunologic (CD4 T-cell count $2.0 \%, 30$ cells $/ \mu \mathrm{L}$ ) and virologic (HIV RNA level 3220 copies $/ \mathrm{mL}, \log 3.51$ ) measures were seen. Due to progressive neurologic symptoms HAART was ceased. The second MRI (Figure 3) scan was performed and showed a progressive lesion in the same regions as described in the previous MRI, but also found new lesions over the midbrain, pons, and medulla predominantly on the left. The patient was discharged approximately 3 weeks after admission.

2.3. Third Admission. The patient was readmitted 1 month later (100 days after onset of symptoms). Immune Reconstitution Inflammatory Syndrome (IRIS) was suspected, and the boy was treated with methylprednisolone $(2 \mathrm{mg} / \mathrm{kg} /$ day $)$ for 5 days. Despite HAART suspension and administration of steroids, his clinical symptoms worsened. The third MRI (Figure 4) scan showed new lesions in the regions of the right brainstem and right hemisphere with gyral enhancement. The patient's mother refused further treatment, he was discharged home, and he subsequently died 1 year later.

\section{Summary}

We report the 2nd case of IRIS associated PML in a perinatally HIV-infected child. Since 1992 there have been reports of 14 HIV-infected children having PML (Table 1) [4-14]. Overall, PML in HIV-infected children has occurred mostly in boys $(9 / 14,75 \%)$, with a median age of 10 years (range: 7-17). Reports have come from Brazil, Hungary, India, Japan, South Africa, Thailand, and USA. Presenting symptoms included: altered speech, hemiplegia, facial palsy, and cerebellar dysfunction. All had significant changes on MRI or CT. Presenting CD4 T-cell counts were low, while viral loads were high. The most common outcome was death. 


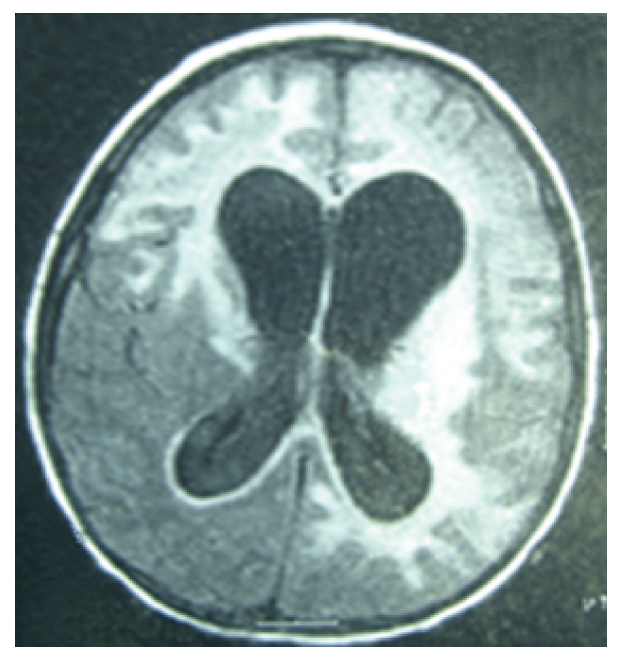

Figure 3: 2nd MRI, 3 1/2 months after onset of symptoms, 3 days post-HAART cessation.

Neuroimaging is an important part of the diagnosis. Multiple bilateral areas of white matter demyelination without contrast enhancement or mass effect are typical findings. For CT imaging these appear hypodense, while on MRI they have either decreased or increased signals depending on the imaging parameters [14-16]. Treatment for PML is based on HAART initiation or optimization, which has shown improved mortality associated with lower HIV RNA plasma viral levels and higher CD4 T-cell count [17-20].

Although rare, cases of PML associated with IRIS occur where there is clinical deterioration despite improvement of immunological and virological measures after the initiation of HAART [21, 22]. This was seen in the case reported here and the other reported case of PML in an HIV-infected child associated with IRIS [10]. Reported in 2004, a 12year-old African boy developed cerebellar dysfunction and hemiparesis 5 weeks after starting HAART. He was started on prednisone and continued on HAART. He subsequently had immunologic and virologic improvement with full clinical recovery. Estimates from HIV-infected adults with PML associated IRIS range from 9-19\%, typically occurring 3-5 weeks after initiation; this is purportedly much less common in children, as it is only sporadically mentioned in the literature $[18,23]$. Therapy for PML associated IRIS has included glucocorticoids in addition to HAART interruption, which have been shown to be both beneficial and to be of no benefit in HIV-infected adults with PML [10, 22, 24-26]. Our patient saw further clinical deterioration, despite a trial of these measures unlike the boy in Africa [10].

PML in HIV-infected adolescents has a wide distribution of ages and geography. Despite the cases presented here, there is limited information about this disease in children. Underdiagnosis is likely to both perpetuate this knowledge gap and discourage physicians from identifying this condition. Additionally, in developing countries, such as Thailand, lack of imaging and laboratory data may further hinder diagnosis.

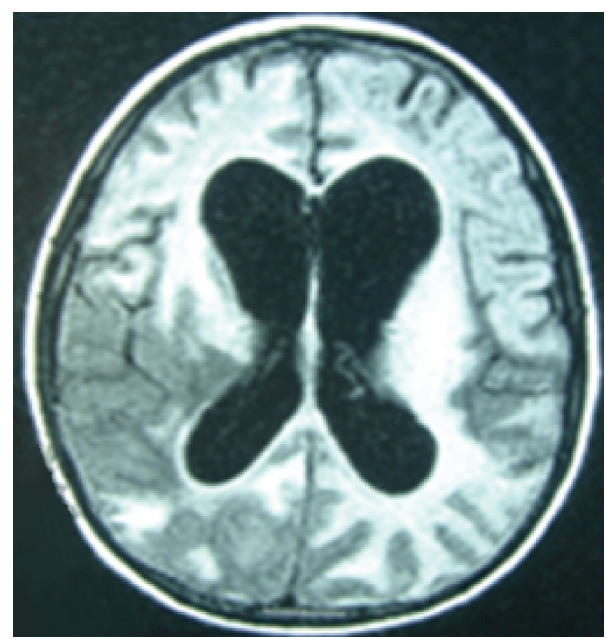

FIGURE 4: 3rd MRI, 4 months after onset of symptoms, 19 days postHAART cessation.

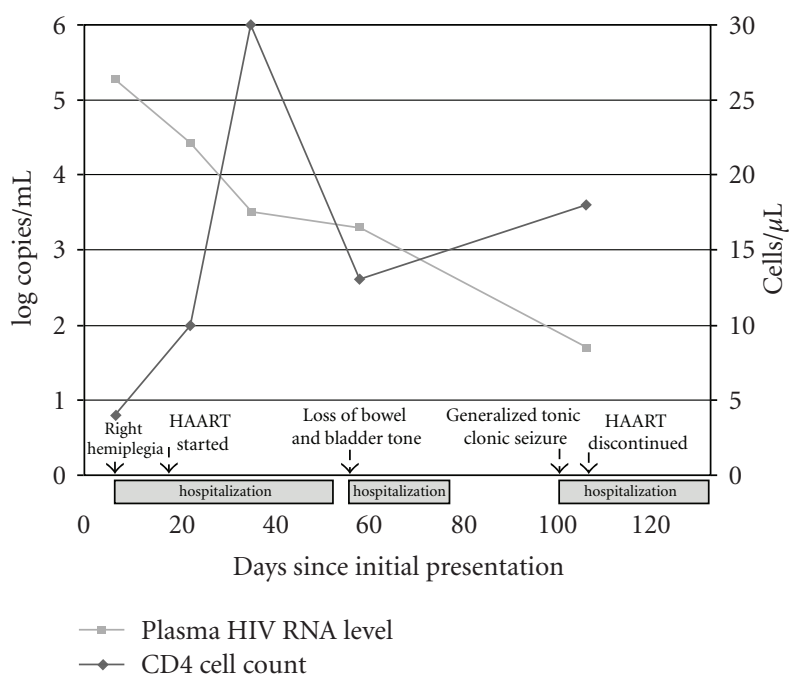

FIGURE 5: Clinical manifestations and plasma HIV RNA and CD4 cell count levels.

Clinicians should then be cognizant of both of this condition and sequelae after HAART, so that prompt diagnosis and treatment can be made. Clear guidelines would be beneficial to clinicians who face these complex patients.

\section{Abbreviations}

3TC: Lamivudine;

AZT: Ziduvodine;

d4T: $\quad$ Stavudine;

ddC: Zalcitabine;

ddI: Didanosine;

EFV: Efavirenz;

HAART: Highly active antiretroviral therapy;

NLF: Nelfinavir;

NVP: Nevirapine. 
International Journal of Pediatrics

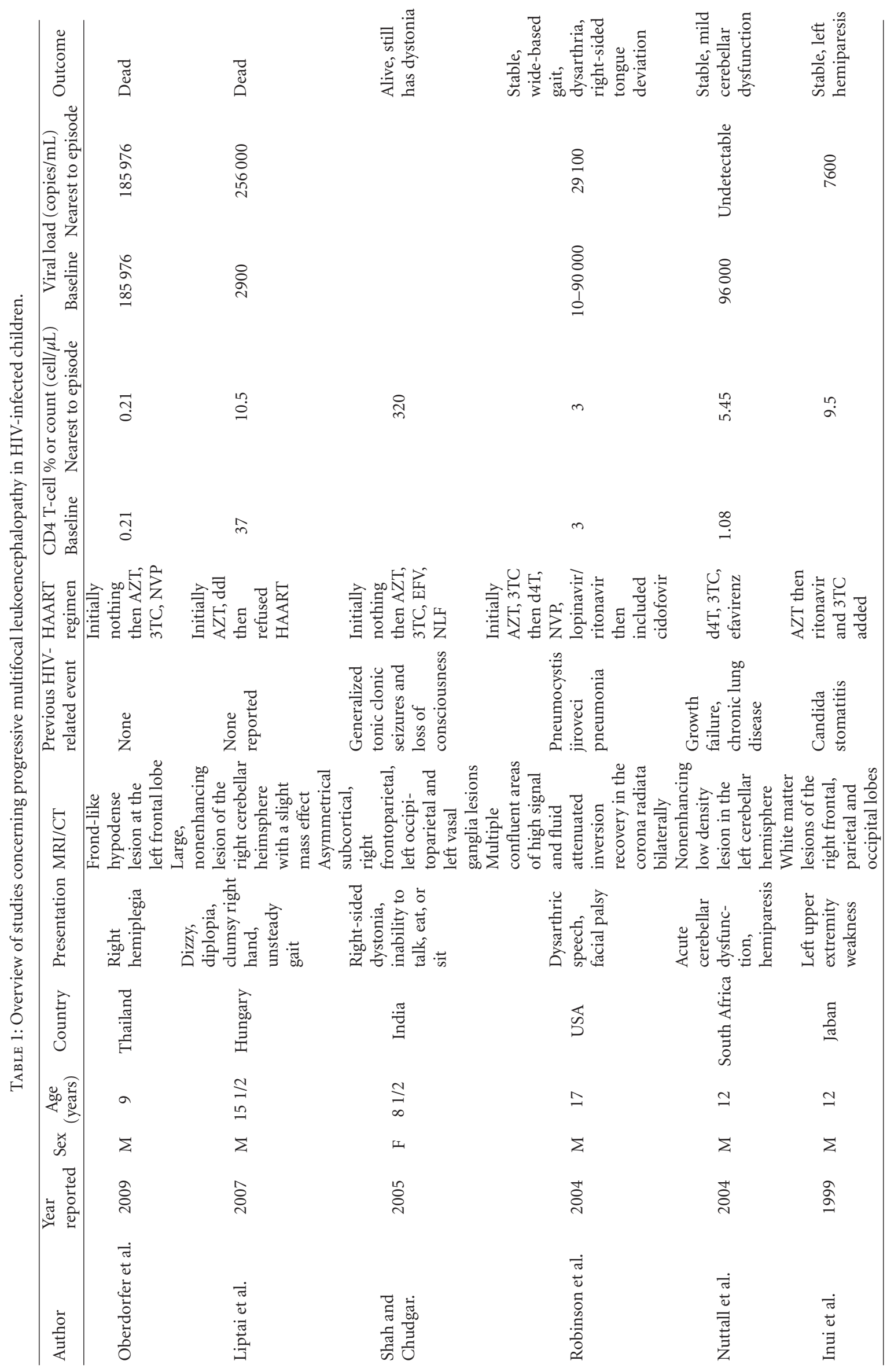




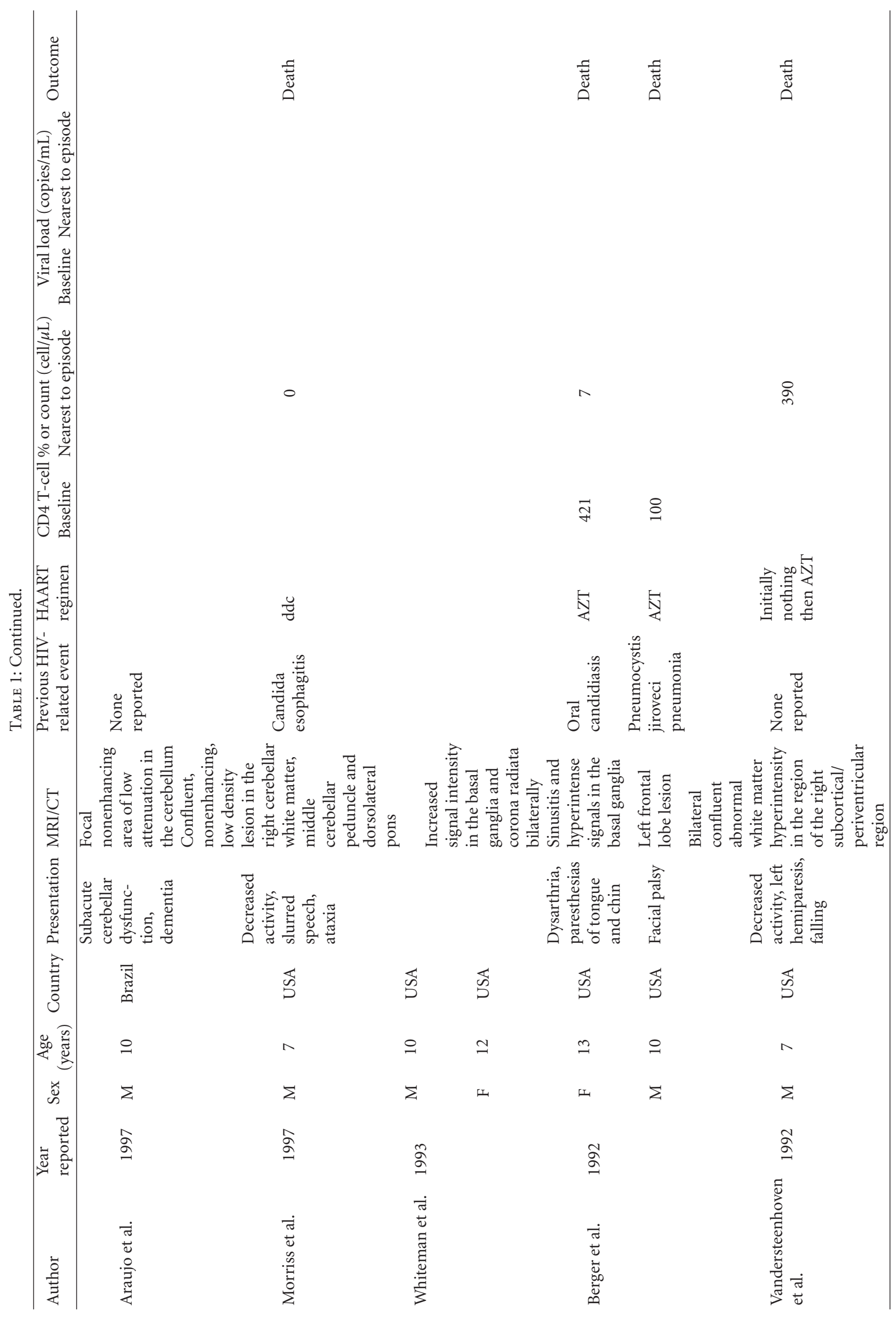




\section{Acknowledgments}

The authors would like to thank Dr. Virat Sirisanthana who provided valuable advice. This work was supported by Faculty of Medicine, Chiang Mai University, Chiang Mai, Thailand (to P. Oberdorfer, K. Katanyuwong, and P. Jpttamala) and by a grant from the NIH/Fogarty Clinical Research Training Scholars Program (to C.H. Washington).

\section{References}

[1] T. Weber, "Progressive multifocal leukoencephalopathy," Neurologic Clinics, vol. 26, no. 3, pp. 833-854, 2008.

[2] B. L. Padgett and D. L. Walker, "Prevalence of antibodies in human sera against JC virus, an isolate from a case of progressive multifocal leukoencephalopathy," Journal of Infectious Diseases, vol. 127, no. 4, pp. 467-470, 1973.

[3] GPO, GPOvir-Z, Government Pharmaceutical Company, Bangkok, Thailand.

[4] A. P. Araujo, H. S. Pereira, R. H. Oliveira, A. C. Frota, J. C. Esperanca, and F. Duarte, "Progressive multifocal leukoencephalopathy in a child with acquired immunodeficiency syndrome (AIDS)," Arquivos de Neuro-Psiquiatria, vol. 55, no. 1, pp. 122-125, 1997.

[5] J. R. Berger, G. Scott, J. Albrecht, A. L. Belman, C. Tornatore, and E. O. Major, "Progressive multifocal leukoencephalopathy in HIV-1-infected children," AIDS, vol. 6, no. 8, pp. 837-841, 1992.

[6] K. Inui, H. Miyagawa, J. Sashihara, et al., "Remission of progressive multifocal leukoencephalopathy following highly active antiretroviral therapy in a patient with HIV infection," Brain and Development, vol. 21, no. 6, pp. 416-419, 1999.

[7] K. Krasinski, W. Borkowsky, and R. S. Holzman, "Prognosis of human immunodeficiency virus infection in children and adolescents," Pediatric Infectious Disease Journal, vol. 8, no. 4, pp. 216-220, 1989.

[8] Z. Liptai, E. Papp, P. Barsi, et al., "Progressive multifocal leukoencephalopathy in an HIV-infected child," Neuropediatrics, vol. 38, no. 1, pp. 32-35, 2007.

[9] M. C. Morriss, R. M. Rutstein, B. Rudy, C. Desrochers, J. V. Hunter, and R. A. Zimmerman, "Progressive multifocal leukoencephalopathy in an HIV-infected child," Neuroradiology, vol. 39, no. 2, pp. 142-144, 1997.

[10] J. J. C. Nuttall, J. M. Wilmshurst, A. P. Ndondo, et al., "Progressive multifocal leukoencephalopathy after initiation of highly active antiretroviral therapy in a child with advanced human immunodeficiency virus infection: a case of immune reconstitution inflammatory syndrome," Pediatric Infectious Disease Journal, vol. 23, no. 7, pp. 683-685, 2004.

[11] L.-G. Robinson, C. A. Chiriboga, S. E. Champion, I. Ainyette, and E. J. Abrams, "Progressive multifocal leukoencephalopathy successfully treated with highly active antiretroviral therapy and cidofovir in an adolescent infected with perinatal human immunodeficiency virus (HIV)," Journal of Child Neurology, vol. 19, no. 1, pp. 35-38, 2004.

[12] I. Shah and P. Chudgar, "Progressive multifocal leukoencephalopathy (PML) presenting as intractable dystonia in an HIV-infected child," Journal of Tropical Pediatrics, vol. 51, no. 6, pp. 380-382, 2005.

[13] J. J. Vandersteenhoven, G. Dbaibo, O. B. Boyko, et al., "Progressive multifocal leukoencephalopathy in pediatric acquired immunodeficiency syndrome," The Pediatric Infectious Disease Journal, vol. 11, no. 3, pp. 232-237, 1992.
[14] M. L. H. Whiteman, M. J. D. Post, J. R. Berger, L. G. Tate, M. D. Bell, and L. P. Limonte, "Progressive multifocal leukoencephalopathy in $47 \mathrm{HIV}$-seropositive patients: neuroimaging with clinical and pathologic correlation," Radiology, vol. 187, no. 1, pp. 233-240, 1993.

[15] M. J. Donovan Post, C. Yiannoutsos, D. Simpson, et al., "Progressive multifocal leukoencephalopathy in AIDS: are there any MR findings useful to patient management and predictive of patient survival?" American Journal of Neuroradiology, vol. 20, no. 10, pp. 1896-1906, 1999.

[16] D. J. Skiest, "Focal neurological disease in patients with acquired immunodeficiency syndrome," Clinical Infectious Diseases, vol. 34, no. 1, pp. 103-115, 2002.

[17] A. Antinori, A. Cingolani, P. Lorenzini, et al., "Clinical epidemiology and survival of progressive multifocal leukoencephalopathy in the era of highly active antiretroviral therapy: data from the Italian Registry Investigative Neuro AIDS (IRINA)," Journal of NeuroVirology, vol. 9, supplement 1, pp. 47-53, 2003.

[18] J. Berenguer, P. Miralles, J. Arrizabalaga, et al., "Clinical course and prognostic factors of progressive multifocal leukoencephalopathy in patients treated with highly active antiretroviral therapy," Clinical Infectious Diseases, vol. 36, no. 8, pp. 1047-1052, 2003.

[19] A. De Luca, M. L. Giancola, A. Ammassari, et al., "The effect of potent antiretroviral therapy and JC virus load in cerebrospinal fluid on clinical outcome of patients with AIDSassociated progressive multifocal leukoencephalopathy," Journal of Infectious Diseases, vol. 182, no. 4, pp. 1077-1083, 2000.

[20] C. M. Marra, N. Rajicic, D. E. Barker, et al., "A pilot study of cidofovir for progressive multifocal leukoencephalopathy in AIDS," AIDS, vol. 16, no. 13, pp. 1791-1797, 2002.

[21] C. Hoffmann, H.-A. Horst, H. Albrecht, and W. Schlote, "Progressive multifocal leucoencephalopathy with unusual inflammatory response during antiretroviral treatment," Journal of Neurology Neurosurgery and Psychiatry, vol. 74, no. 8, pp. 1142-1144, 2003.

[22] A. Safdar, R. J. Rubocki, J. A. Horvath, K. K. Narayan, and R. L. Waldron, "Fatal immune restoration disease in human immunodeficiency virus type 1-infected patients with progressive multifocal leukoencephalopathy: impact of antiretroviral therapy-associated immune reconstitution," Clinical Infectious Diseases, vol. 35, no. 10, pp. 1250-1257, 2002.

[23] P. Cinque, S. Bossolasco, A. M. Brambilla, et al., "The effect of highly active antiretroviral therapy-induced immune reconstitution on development and outcome of progressive multifocal leukoencephalopathy: study of 43 cases with review of the literature," Journal of NeuroVirology, vol. 9, supplement 1, pp. 73-80, 2003.

[24] J. V. Martinez, J. V. Mazziotti, E. D. Efron, et al., "Immune reconstitution inflammatory syndrome associated with PML in AIDS: a treatable disorder," Neurology, vol. 67, no. 9, pp. 1692-1694, 2006.

[25] A. Vendrely, B. Bienvenu, J. Gasnault, J. B. Thiebault, D. Salmon, and F. Gray, "Fulminant inflammatory leukoencephalopathy associated with HAART-induced immune restoration in AIDS-related progressive multifocal leukoencephalopathy," Acta Neuropathologica, vol. 109, no. 4, pp. 449455, 2005.

[26] A. Venkataramana, C. A. Pardo, J. C. McArthur, et al., "Immune reconstitution inflammatory syndrome in the CNS of HIV-infected patients," Neurology, vol. 67, no. 3, pp. 383$388,2006$. 


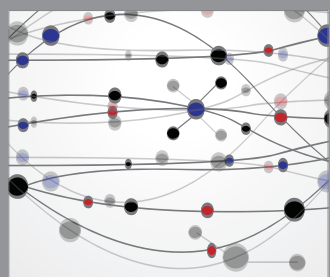

The Scientific World Journal
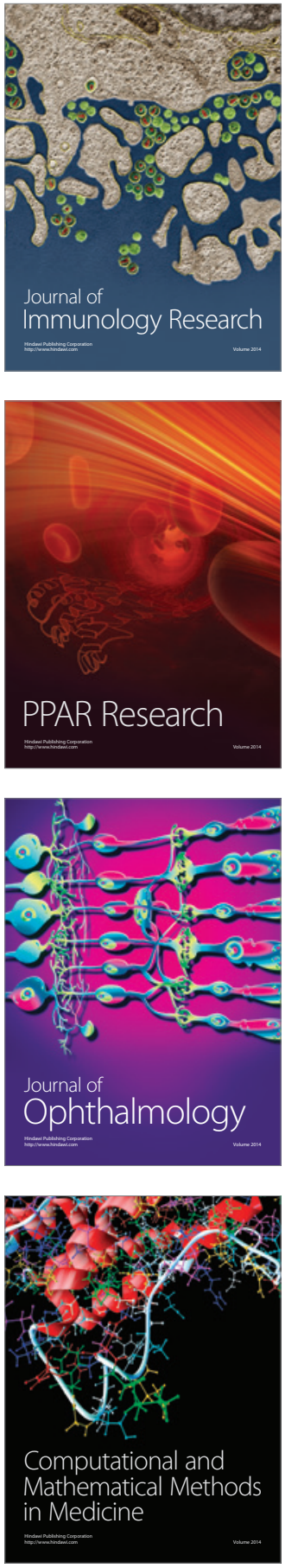

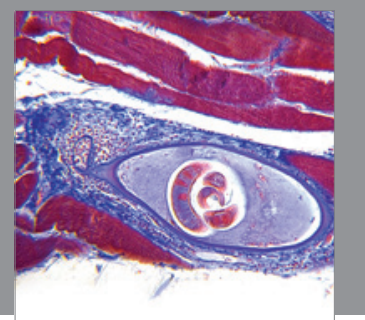

Gastroenterology

Research and Practice
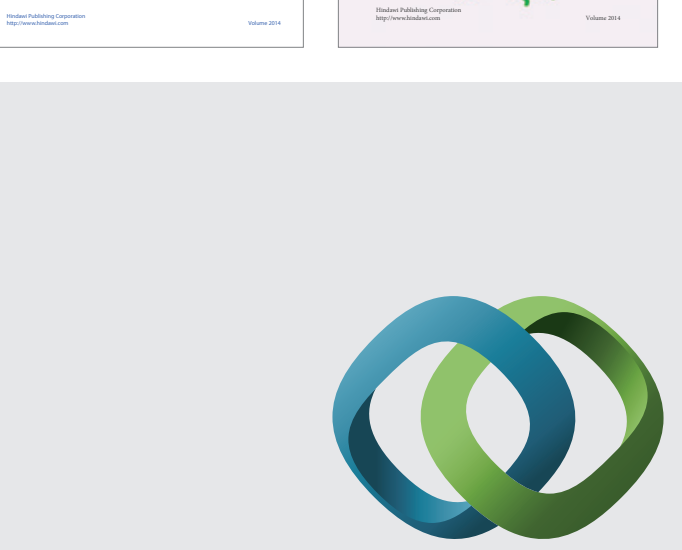

\section{Hindawi}

Submit your manuscripts at

http://www.hindawi.com
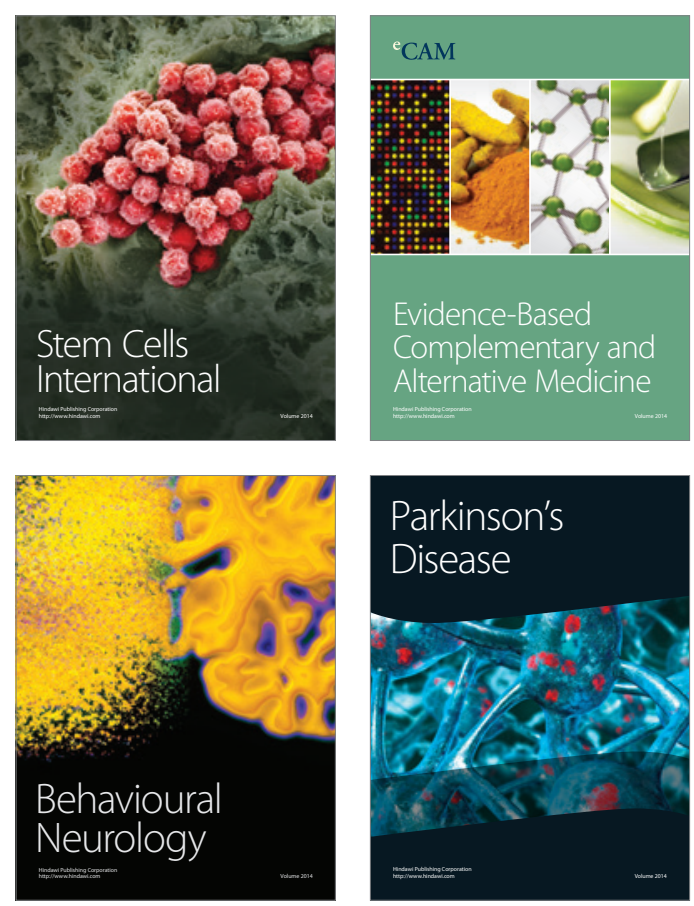

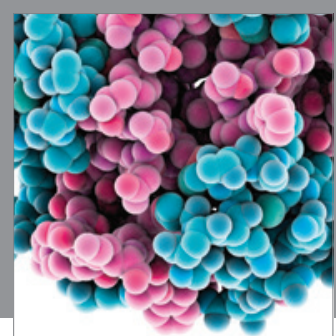

Journal of
Diabetes Research

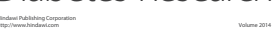

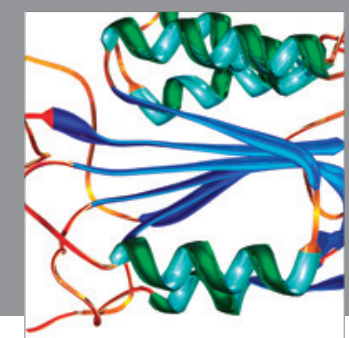

Disease Markers
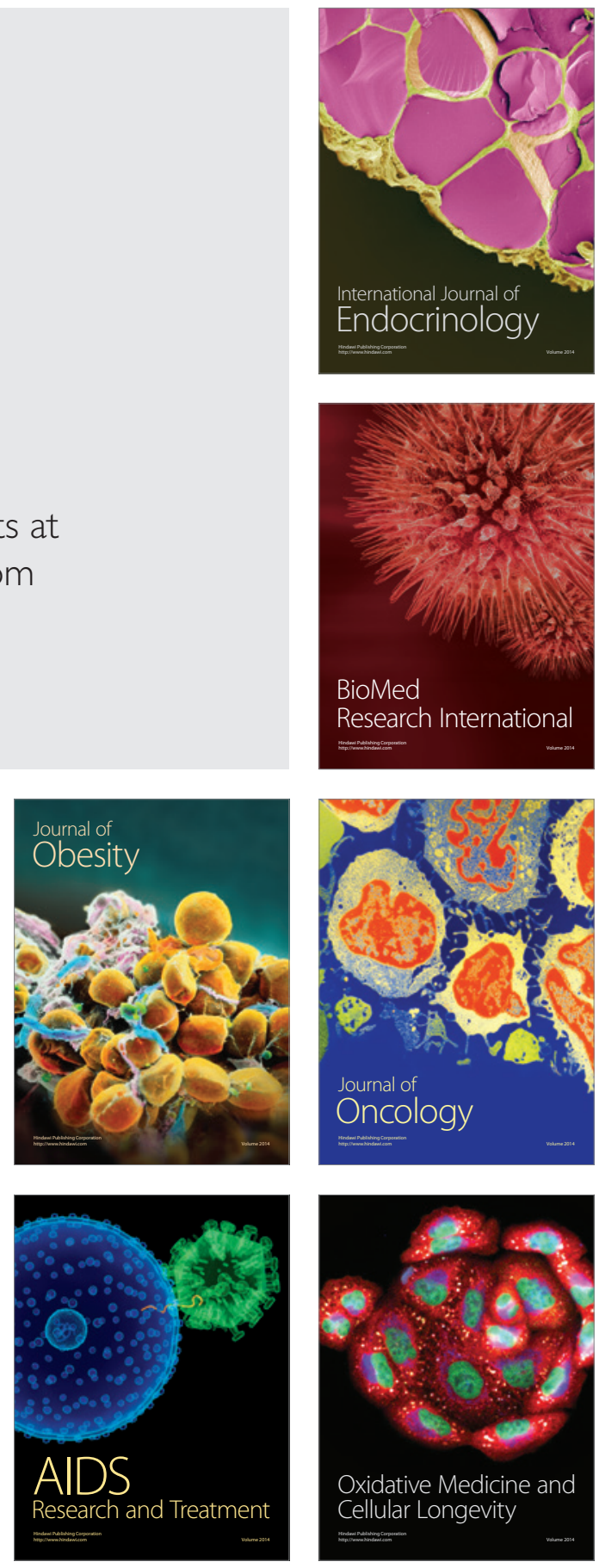